\title{
Intrinsic and extrinsic wiring of CA3: Indications for connectional heterogeneity
}

\author{
Menno P. Witter ${ }^{1}$ \\ Kavli Institute for System Neuroscience and Centre for the Biology of Memory, Norwegian University of Science and Technology, \\ Trondheim N0-7489, Norway; Institute for Clinical and Experimental Neurosciences, Department of Anatomy \& Neurosciences, \\ VU University Medical Center, Amsterdam 1007 MB, The Netherlands
}

\begin{abstract}
Within the framework of a special issue on CA3, it was deemed relevant to summarize what is known about the extrinsic and intrinsic wiring of CA3 as a basis for other contributions. Here, I have aimed to update already existing excellent reviews on the subject and to raise the issue whether or not the known architecture of the field supports the generally accepted notion that CA3 is particularly wired to function as an autoassociative network. The data reviewed strongly support this notion but in addition point to connectional heterogeneities that may point to functional specializations in CA3, on top of its role as an autoassociative network uniquely relevant to efficient encoding and recall of information.
\end{abstract}

A major source of input to CA3 is originating from bilateral CA3 itself. This distinguishing feature has attracted the attention of many researchers interested in understanding the functional relevance of CA3. This has lead to the well-established concept of autoassociative networks as the most striking and therefore functionally determinant feature of the CA3 network. In most functional analyses of CA3, be it modeling, electrophysiological, or lesion studies, the presence of this strong autoassociative network is taken as the stepping stone underlying its functions, assuming that this key feature holds throughout CA3; that is, no differences in the overall wiring are present (Marr 1971; McNaughton and Morris 1987; Treves and Rolls 1994; Hasselmo et al. 1995). Comparable to recent insights with respect to the architecture of the subiculum (Witter 2006), the concept of a homogeneous CA3 does not accurately present what is currently known about the connectivity of CA3. Although already partially described in an earlier review (Amaral and Witter 1989), additional data on the overall wiring of CA3 indeed indicates that architectural heterogeneities are present. Although more subtle perhaps than in the subiculum and in CA1 for that matter (Amaral 1993; Witter 2006), this may have consequences for how we perceive CA3. The aim of this review is not to provide an all-inclusive description of what we know about the anatomical organization of CA3 but, in contrast, to highlight those features of the architecture suggesting that only part of CA3 should be perceived as the autoassociative network "pur sang" and that other portions combine this associate feature with specific inputoutput relations, for which the functional implications yet have to be established (see de Almeida et al. 2007, this issue).

\section{Neurons in CA3}

The principal neuronal cell type of the hippocampus is the pyramidal cell, which makes up the vast majority of neurons in the pyramidal cell layer. Pyramidal cells have a basal dendritic tree that extends into stratum oriens and an apical dendritic tree that extends to the hippocampal fissure (Ramón and Cajal 1911; Lorente de Nó 1934; Ishizuka et al. 1990, 1995; Turner et al. 1995; Wittner et al. 2007). CA3 pyramidal cells are characterized by having unique very complex dendritic postsynaptic structures,

\footnotetext{
1 Corresponding author.
}

E-mail menno.witter@ntnu.no; fax 47-73598294.

Article is online at http://www.learnmem.org/cgi/doi/10.1101/lm.725207. called thorny excrescences, a feature that they share only with some neurons in the hilus (Frotscher et al. 1991; Chicurel and Harris 1992; Lauer and Senitz 2006; Witter 2007). Although at first impression, pyramidal cells look quite similar, and no striking differences in electrophysiological properties are apparent, the dendritic length and organization of CA3 pyramidal cells is quite variable along the transverse axis (Ishizuka et al. 1995; Turner et al. 1995). At dorsal levels, the smallest cells (with a soma size of $\sim 300 \mu^{2}$ or $20 \mu \mathrm{m}$ in diameter) are located within the limbs of the dentate gyrus and have a total dendritic length of $8-11 \mathrm{~mm}$. The largest cells (with a soma size of $\sim 700 \mu \mathrm{m}^{2}$ or 30 $\mu \mathrm{m}$ in diameter), which are located distally in the field, have total dendritic lengths of 16-19 $\mathrm{mm}$. More ventrally positioned cells apparently have an increased dendritic length compared with dorsally positioned cells (Turner et al. 1995). Note that total dendritic length does not appear to be related to axonal length since pyramidal cells in the proximal part of CA3, those with the shortest overall dendritic arbor, have the largest axonal trees. More ventral pyramidal cells, having the largest dendritic tree also tend to have larger axonal trees compared with dorsally positioned ones. Interestingly, ventral cells apparently have almost no thorny excrescences (Li et al. 1994).

The distribution of the dendritic trees of CA3 pyramidal cells further varies depending on where the cell body is located along the transverse axis. Cells located within the limbs of the dentate gyrus have little or none of their dendrites extending into the stratum lacunosum-moleculare, whereas cells located close to the border with CA2 have about the same percentage of their dendritic tree in stratum lacunosum-moleculare as in stratum radiatum. Taken together with differences in the laminar distribution of main inputs along the transverse axis (see below), this may lead to gross connectional differences along the transverse axis (Ishizuka et al. 1995).

Although pyramidal neurons are by far the most numerous neurons in CA3, there is also a fairly heterogeneous group of interneurons. Most types of interneurons are not exclusive for CA3 but are found in all the hippocampal subfields, and since their main morphological and connectional features have been summarized extensively in a number of reviews, we will not describe them in any detail. Interneurons are present in all layers of $\mathrm{CA} 3$, and their dendritic tree, i.e., receptive field, and/or their axonal arbor, i.e., projection field, are strongly related to the specific terminal distributions of major inputs to CA3 (Freund 
and Buzsaki 1996; Witter and Amaral 2004; Somogyi and Klausberger 2005; Amaral and Lavenex 2006).

\section{CA3 connectivity within the hippocampal region}

CA3-to-CA3 connectivity is only one, though characteristic, element of the architecture of CA3. In order to fully grasp the functional relevance of CA3, other connections should be integrated. Here the aim is to provide a short overview of the organizations of associative and commissural connections and relate these to the CA3 connections with other domains of the hippocampal region, in particular the dentate gyrus, CA1, and the entorhinal cortex. Note that CA3 appears not to be connected to the subiculum, the pre- and parasubiculum, as well as with the perirhinal and parahippocampal (postrhinal in rodents) cortices (Witter and Amaral 2004), although cells, particularly those in ventral CA3, occasionally send axon collaterals into the subiculum (Ishizuka et al. 1990; Li et al. 1994).

\section{Hippocampal projections originating in CA3}

It is relevant to point out that the CA3-to-CA3 projections are typically called the associational connections, whereas the CA3 projections to the CA1 field are typically referred to as Schaffer collaterals, honoring the original description (Schaffer 1892). CA3 neurons also issue strong commissural projections to contralateral CA3 and CA1. The first two are true collaterals, and the same is likely to hold true for all of the commissural fibers as well; all these projections thus potentially carry the same information. First, the associative system will be described, followed by the Schaffer collateral system. This section will be completed with a description of the commissural projections.

\section{The CA3 associational system}

Local axon collaterals of CA3 axons make preferentially asymmetrical, thus most likely representing excitatory synapses, contacting dendrites of interneurons (Sik et al. 1993; Wittner et al. 2006). It is likely that excitatory synapses also exist with spines of CA3 pyramidal cells, on the basis of well-established monosynaptic activation of CA3 neurons by recurrent collaterals (MacVicar and Dudek 1980;Miles and Wong 1983, 1986), as well as the finding that the commissural input from CA3 to CA3 forms asymmetrical synapses with CA3 pyramidal cells, both in stratum radiatum and in stratum oriens (Andersen et al. 1969; Andersen 1975).

The organization of the associational projections from CA3 to CA3 follows a few systematic principles that have been described essentially in two detailed tracing studies using either larger injections of anterogradely transported tracers (Ishizuka et al. 1990; see also Amaral and Witter 1989) or intracellular filling of individual CA3 pyramidal cells (Ishizuka et al. 1990; Li et al. 1994). Although the data in the two studies are largely consistent, some differences are apparent that most likely reflect the huge variability between the axonal structures of individual CA3 neurons, as well as different methodologies used. Density and extent of local connectivity in CA3 is inversely related to the origin along the proximodistal axis. CA3 pyramidals embedded within the extent of the dentate gyrus do not seem to contribute much to the intrinsic associative system. Their axons are restricted both along the proximodistal axis as well as along the longitudinal (dorsoventral) axis to the level of the parent cell(s). Cells with an increasingly more distal position in CA3 tend to exhibit increased associational axonal collaterals. According to the anterograde uptake study, cells in the middle as well as distal portions of CA3 project throughout the extent of the transverse axis, although this takes place at different levels along the lon- gitudinal axis: At levels ventral to the level of origin, axonal distribution shifts to a more proximal position, whereas at levels dorsal to the level of origin, the terminal field gradually shifts toward a more distal position (Ishizuka et al. 1990). In contrast, in the study of Li et al. (1994), it is stressed, on the basis of intracellularly filled neurons, that any CA3 pyramidal preferentially targets a longitudinal strip of CA3 of several hundred microns anterior and posterior to the cell body but restricted along the transverse axis to the region of the parent cell body.

The proximodistal origin also apparently relates to the radial distribution of the axons (Fig. 1), such that proximal neurons preferentially project to stratum radiatum, whereas axons from increasingly more distal cells distribute more to stratum oriens (Li et al. 1994). To further complicate this pattern, the radial distribution also shifts position in relation to the level along the longitudinal axis. At levels dorsal to the cell(s) of origin, axons tend to shift to stratum oriens, whereas at levels ventral to the origin, axons show some preference for stratum radiatum (Ishizuka et al. 1990). Finally, the origin along the transverse axis is reflected in a corresponding shift in axonal distribution along the longitudinal axis (not indicated in Figs. 1, 2). Whereas proximal CA3 preferentially projects to levels dorsal to the origin, mid portions of CA3 project equally to levels dorsal and ventral to the origin and distal CA3 preferentially project to levels ventral to the level of origin along the long axis (Ishizuka et al. 1990).

\section{The CA3-to-CA1 system-Schaffer collaterals}

Comparable to the situation in CA3, and not quite unexpected in view of the fact that we are dealing with collateral systems, the overall postsynaptic targets in CA1 for CA3 fibers comprise both interneurons and pyramidal cells (Andersen 1975; Sik et al. 1993; Sorra and Harris 1993; Wittner et al. 2006). With respect to the topographical organization of the projections from CA3 to CA1, the most detailed information is provided in the studies by Ishizuka et al. (1990) and Li et al. (1994). The results, as described in those studies, largely confirm previously published accounts on the presence and overall organization, using less sensitive tracing methods (Raisman et al. 1966; Swanson et al. 1978). Overall, CA3 projections distribute in stratum radiatum and stratum oriens of CA1, whereas almost no fibers are present in the pyramidal cell layer. Almost without exceptions, the longitudinal extent of the projections to CA1 is larger than that of the corresponding associative CA3 projections. Irrespective of the level of origin, projections do extend to levels both dorsal as well as ventral to the level of origin; however, there is a preferential direction of the projections that relates to the transverse level of origin. Neurons with a proximal location close to or inside the hilus preferentially project to more dorsal levels, whereas more distal origins result in a shift to more ventral levels. Irrespective of the location of the neuron of origin though, the projections exhibit differences in radial distribution along the long axis of CA1. At more dorsal levels, collaterals tend to be located deeper in stratum radiatum and in stratum oriens, whereas at progressively more ventral levels, the fibers shift toward a more superficial position in stratum radiatum and less dense innervation in stratum oriens. This pattern is thus similar to that described for the associative CA3-CA3 projections (Fig. 1). The transverse position of the parent CA3 neuron does relate, at and around the level of origin to two other features. First, proximal projections tend to distribute somewhat more distally in CA1, and more distal CA3 cells project preferentially to more proximal portions of CA1 (Fig. 1). Furthermore, proximally originating projections terminate more superficially in stratum radiatum than do distal projections, which distribute deeper in stratum radiatum and in oriens (Ishizuka et al. 1990; Li et al. 1994). 


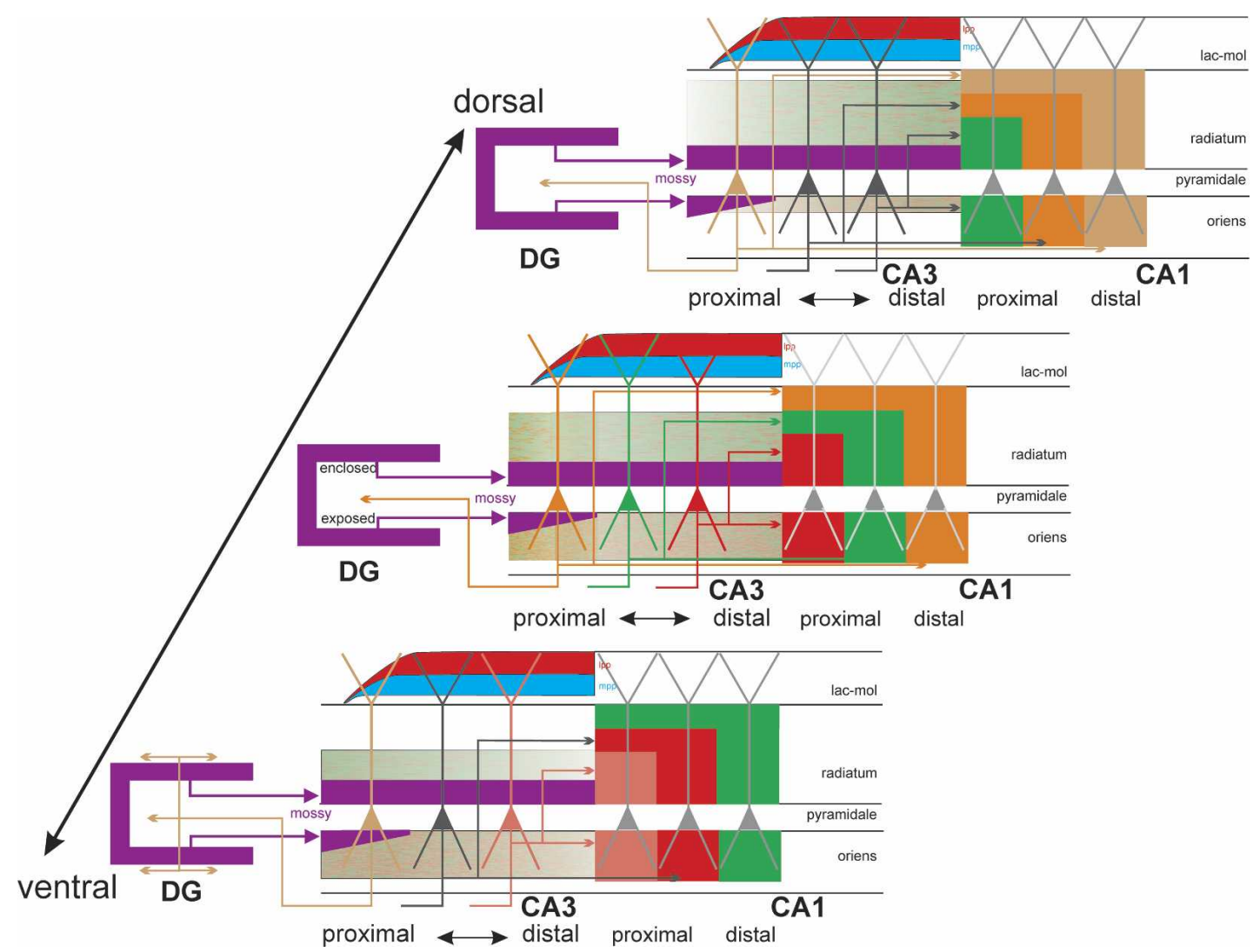

Figure 1. Connections of CA3. Three different levels (panels) along the dorsoventral (septotemporal) axis of CA3 are shown, bordered by CA1 (left) and dentate gyrus (DG; right). The central panel shows three color-coded neurons with different positions along the transverse (proximo-distal) axis of CA3. Collateral distribution is shown for both the association and Schaffer system along the transverse and longitudinal axes, using color coding related to the parent cell bodies in the central panel. Note the transverse shifts of both the association and the Schaffer system along the long axis but in the opposite direction (for details, see text and Fig. 2). Also indicated is the radial shift of the association system along the longitudinal axis as well as the very limited longitudinal and transverse extent of the proximally arising association system (orange/green terminal field in radiatum and oriens at the level of the central panel only). This contrasts strongly with the more widespread distribution of the more distally arising components (green/red terminal fields in all three panels). Cells in proximal CA3, receiving less perforant path input (indicated by red and blue, lateral [lpp] and medial [mpp]) but strong infrapyramidal mossy fiber input (purple), project back to the hilus of the dentate gyrus, with at more ventral levels (lower panel) an increasing component that distributes to the inner molecular layer. Not indicated is the strong longitudinal component of the mossy fiber system that distributes along $\sim 20 \%-25 \%$ of the long axis of distal CA3.

Two more observations are relevant in the context of this article (data not shown). First, it has been observed that the projections to CA1, although generally exhibiting an "en passant" type of organization (Sorra and Harris 1993; Shepherd and Harris 1998), have a tendency to concentrate their synapses, forming patches of dense innervation alternating with less densely innervated areas, showing an interpeak distance of $\sim 500 \mu \mathrm{m}$ ( $\mathrm{Li}$ et al. 1994). This may indicate that individual CA3 neurons preferentially single out CA1 neurons as their preferred target. However, it cannot be excluded that this finding, reported in only one study, may be the result of incomplete axonal filling. In addition, differences along the longitudinal axis have been described by $\mathrm{Li}$ et al. (1994). Although for all levels of CA3 it appears that cells in the proximal part of $\mathrm{CA} 3$ do not contribute extensively to the associative CA3 projection, only the cells in the more dorsal portions project densely to more distal portions of CA1 and weakly to the hilus of the dentate gyrus. Proximal CA3 neurons at ventral levels seem to contribute less to the Schaffer collaterals to CA1 but, in contrast, project densely to the dentate hilus as well as to the inner molecular layer of the dentate, where their terminal field coincides with that of the dentate association and commissural system (see below). Also, such ventral cells provide a denser input to CA3 compared with their more dorsally posi- tioned counterparts. Although not described in the article by Ishizuka et al. (1990), their tracing data show a comparable shift if one compares the labeling in CA1 that results from dorsal versus ventral injections in CA3. The relevance of this heterogeneity along the longitudinal axis of CA3 remains to be explored.

\section{CA3 contralateral connections}

In the rat, single pyramidal cells in CA3 distribute axonal branches not only ipsilaterally but also contralaterally (Blackstad 1956; Andersen et al. 1966; Gottlieb and Cowan 1973; Swanson et al. 1978, 1980; Voneida et al. 1981; Finch et al. 1983; Ishizuka et al. 1990; Li et al. 1994). The detailed topography of the commissural connections has not been as thoroughly investigated as the ipsilateral connections, but it appears an image of the ipsilateral organization for both the projections to CA3 as to CA1 (Swanson et al. 1978). Also the synaptic organization of both ipsilateral and commissural projections is quite similar, with the majority of synapses being excitatory and terminating both on pyramidal cells (Westrum and Blackstad 1962; Andersen 1975) and on a variety of interneurons (Frotscher and Zimmer 1983; Leranth and Frotscher 1983; Frotscher et al. 1984). It is finally of interest that, in particular, the commissural system has been 


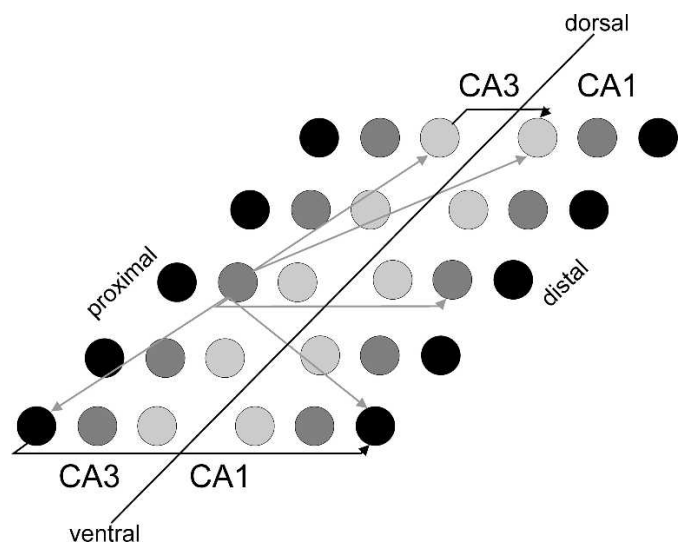

Figure 2. Schematic representation of the relationships of the association and Schaffer system along the longitudinal and transverse axes, taken from one cell centered in CA3 (dark gray in the central row) as the starting point. This cell connects to the dark gray coded CA1 cell at the same longitudinal level but also extends collaterals along the long axis. These projections exhibit a transverse shift along the longitudinal axis such that at ventral levels, interconnected parts of CA3 and CA1 (black coded cells) are targeted, and the same holds true for the light gray coded pair at more dorsal levels. This organization implies that activity originating from a particular node in CA3 is widely distributed onto the CA1 network, with a preference to interconnected sets of neurons.

studied in a variety of species. These studies all indicate that species differences are present with respect to whether or not the commissural connections are present and, if present, how they are organized with respect to their longitudinal and radial distribution (Amaral et al. 1984; Demeter et al. 1985; van Groen and Wyss 1988).

\section{CA3 connectivity with the dentate gyrus}

Neurons in CA3, both pyramidal cells as well as interneurons, receive a massive input from granule cells in the dentate gyrus, the so-called mossy fiber system. In contrast to the well-accepted view that projections within the hippocampal formation are largely if not exclusively unidirectional, implying that CA3 does not project to the dentate gyrus, there is now substantial evidence to support such back-projections. In this section, these back-projections will be described first, in order to complete the description of the intrahippocampal CA3-projection system. Subsequently, a description of the mossy fiber system will be provided.

\section{CA3 to dentate projections}

These connections have not been described in the initial Golgi studies or in subsequent tracing studies using anterograde degeneration, anterograde tracing with radioactively labeled amino acids, or even using the more recently introduced sensitive lectins and dextran-amines. However, intracellular filling consistently showed that pyramidal cells in the most proximal portion of CA3, embedded within the blades of the dentate granule cell layer issue collaterals that reach the hilar region. Although the exact border between the dentate hilus and field CA3 may still be a matter of some controversy, there is no doubt as to whether such projections exist (Ishizuka et al. 1990; Buckmaster et al. 1993; Li et al. 1994; Scharfman 1994). Although initially described as sparse, which may be true at more dorsal levels of the hippocampal formation, at more ventral levels, CA3 neurons actually densely innervate the dentate gyrus, not only the hilus but numerous CA3 axon collaterals also terminate in the most inner portions of the dentate molecular layer (Li et al. 1994). Although the functional relevance of these observations remains unclear yet, it has been proposed to be related to the relative proneness of the ventral hippocampus to generate epileptic seizures.

\section{Dentate to CA3 projections-Mossy fibers}

The entire transverse or proximodistal extent of CA3 receives mossy fiber input originating from dentate granule cells (Ramón and Cajal 1911; Lorente de Nó 1934; Blackstad et al. 1970; Swanson et al. 1978; Claiborne et al. 1986; Gaarskjaer 1986). Mossy fibers provide en passant presynaptic terminals (Amaral and Dent 1981; for review, see Henze et al. 2000) that are unique with respect to size, anatomical complexity, and the fact that they are correlated with likely complex postsynaptic specializations called thorny excrescences. It has been inferred that a single mossy fiber can make as many as 37 synaptic contacts with dendrites of a single CA3 pyramidal cell and that a single CA3 pyramidal cell may receive convergent input from 72 granule cells (Amaral and Lavenex 2006). There is conflicting data concerning the question whether a single mossy terminal, which generally has multiple active zones (Claiborne et al. 1986; Chicurel and Harris 1992; Acsady et al. 1998), interacts with only one CA3 cell or can have contacts with multiple pyramidal cells (Galimberti et al. 2006). In addition to the mossy fibers, there are also thin collaterals that emanate from the parent axon or from mossy terminals. These collaterals appear to preferentially terminate on cells other than the pyramidal cells, i.e., local circuit neurons (Claiborne et al. 1986; Seress et al. 1992; Soriano and Frotscher 1993; Frotscher et al. 1994; Acsady et al. 1998).

The anatomical organization of the mossy fiber projections indicates that the influence exerted by granule cells on CA3 pyramidals depends on the position along the transverse axis of the dentate gyrus (DG), since the proximal portion of CA3 is innervated preferentially by neurons in the exposed (infrapyramidal) blade, the crest and the adjacent portion of the enclosed (suprapyramidal) blade of the DG (Claiborne et al. 1986). The distal portion of CA3 receives mossy fiber input preferentially from granule cells in the enclosed blade of DG. Moreover, proximally in CA3, mossy fibers distribute deep to, within, and superficial to the pyramidal cell layer. These three different components of the mossy fiber projection are called the infrapyramidal, intrapyramidal, and suprapyramidal mossy fiber pathways, respectively. The suprapyramidal mossy fibers form stratum lucidum, and at mid and distal portions of CA3, stratum lucidum virtually contains all mossy fibers targeting pyramidal cells in CA3. Mossy fibers that terminate on basal dendrites of proximally positioned CA3 neurons originate preferentially from the exposed blade, whereas the suprapyramidal component preferentially originates from neurons in the enclosed blade of DG (Fig. 1). This suggests that inputs originating from different parts of DG may also exert differential influence along the dendritic tree of individual CA3 pyramidals as well as may selectively innervate certain groups of CA3 neurons. These findings are of functional interest in at least a number of ways. First, it has been reported that functional differences may be present along the transverse axis of the dentate granule cell population (Hara et al. 1990; Jaarsma et al. 1992; Scharfman et al. 2002; Choi et al. 2003; Witter 2007). Second, variations in the relative size/extent of the infrapyramidal pathway have been reported such that behavioral profiles apparently correlate to the extent of infrapyramidal mossy fiber innervation (Lipp et al. 1987, 1988; Schopke et al. 1991; Hausheer-Zarmakupi et al. 1996).

In general, the projection from a single neuron or from a small group of neighboring neurons distributes axons within a fairly limited longitudinal extent that hardly ever covers more than $400-500 \mu \mathrm{m}$, which coincides with their level of origin 
(Blackstad et al. 1970; Claiborne et al. 1986). There is, however, a noticeable exception, already reported by Lorente de Nó (1934) (see also McLardy and Kilmer 1970; Swanson et al. 1978), in that mossy fibers abruptly change their course from an overall transverse orientation to a longitudinal one, once they reach the distal end of CA3. The extent of the longitudinal component depends on the dorsoventral level of origin, in that granule cells at dorsal levels distribute mossy fibers ventrally for $\sim 2 \mathrm{~mm}$. The more ventral the origin, the less the longitudinal projection is developed, such that granule cells at the ventral dentate have little or no longitudinal component (Swanson et al. 1978). The longitudinal component of the mossy fiber projection appears synaptically indifferent from the transverse component (Acsady et al. 1998).

It is therefore safe to conclude that the anatomical organization of the mossy fiber system indicates that current conceptions of CA3 as having a homogeneously wired architecture are incorrect or at least incomplete. Cells at different transverse positions receive inputs from cells in the dentate gyrus that in turn are different in either their connectivity or functionally. In addition, at the most distal end of the dorsal part of CA3, a population of CA3 pyramidal cells most likely integrates inputs from the entire dorsal tip of the dentate gyrus, a feature that is absent at proximal and mid-transverse levels as well as at ventral CA3 levels. Whether this dorsally existing longitudinal integrative connection is related to the reported preferential involvement of the dorsal portion in spatial memory remains to be investigated.

\section{EC-CA3 projections}

The second largest cortical input to CA3 neurons originates in the entorhinal cortex, and this projection has been substantiated in a number of different species, including the rat, mouse, cat, monkey, rabbit, and guinea (Steward 1976; Amaral and Witter 1989; Witter 1989, 1993; Witter et al. 1989a,b; Yeckel and Berger 1990; Do et al. 2002; van Groen et al. 2003). Although in earlier reports a return projection from CA3 to entorhinal cortex has been described (Swanson et al. 1978), more recent sensitive anterograde tracing experiments have not confirmed those reports, indicating that the major hippocampal projections to the entorhinal cortex originate in CA1 and the subiculum (Witter and Amaral 2004).

In rat and monkey, neurons in layer II project not only to the dentate gyrus but also to CA3 (Steward and Scoville 1976; Witter and Amaral 1991), and it is likely that both originate as collaterals from the same neurons (Tamamaki and Nojyo 1993). In contrast, in the mouse, at least in one of the strains (C57BL/ $6 \mathrm{~J}$ ), layer II cells appear to only project to the dentate gyrus and not extend collaterals to other hippocampal subfields (van Groen et al. 2003). Although this appears a striking species difference, emphasized by several investigators, it is likely not to have general validity since recent unpublished data in the same strain but bred using a different breeding scheme clearly show that the projection originating from layer III does not terminate in CA3 (J. Suh and S. Tonegawa, pers. comm.).

The overall distribution patterns of the entorhinal-to-CA3 projection have not been described in detail, although in many anatomical accounts of the perforant path, reference is made to a projection to CA3. In species where the pathway has been studied in some detail, it appears to follow organization principles very similar to those that govern the projection from entorhinal layer II to the dentate gyrus (Steward 1976; Witter 1989). Generally, two components are differentiated that have their exclusive origin in the two main subdivisions of the entorhinal cortex, generally referred to as lateral and medial entorhinal cortex. Projections from the lateral entorhinal cortex terminate in the outer half of stratum lacunosum-moleculare of CA3, whereas those from the medial subdivision terminate deep to the lateral fibbers, i.e., in the deeper half (Fig. 1). The synaptic organization is also likely to be comparable to that described for the dentate gyrus, such that main postsynaptic targets for the excitatory entorhinal fibbers are spines on apical dendrites of pyramidal cells, complemented by a much lower percentage of synapses onto interneurons (Nafstad 1967; Witter et al. 1992). On the basis of the distribution of apical dendrites as seen in intracellularly filled CA3 neurons, it has been reported that neurons in the most proximal portion of CA3 most likely are largely devoid of entorhinal input since their dendrites do not reach into the terminal zone in CA3. It should be pointed out that as soon as CA3 neurons are positioned closer to the end of the dentate granule cell blades, they do give rise to obliquely oriented apical dendrites extending into stratum lacunosum-moleculare and thus likely receiving entorhinal input. However, assuming that the density of apical dendrites as well as entorhinal terminals in that particular area is not different from the remaining part of CA3, the likelihood for a particular dendrite to be contacted by entorhinal input is lower than is the case for more distally positioned pyramidal cells (Ishizuka et al. 1990; Li et al. 1994).

\section{CA1-to-CA3 projections}

In addition to the projection from CA3 back to the dentate gyrus, there have been reports of projections to CA3 that originate in CA1. However, in clear contrast to the former projection, the latter originates from GABAergic neurons in CA1 (Sik et al. 1994, 1995). These GABAergic projections most likely are part of a larger and more widespread intrahippocampal GABAergic system, likely to effect large portions of the hippocampus (Gulyas et al. 2003).

\section{Connections outside the hippocampal region}

The connectivity of CA3 with structures outside the hippocampal region is rather limited. The main nonhippocampal connection of CA3 is with the septal complex, in that CA3 receives input from the medial septum/diagonal band complex and projects preferentially to the lateral septal nuclei (see below). Other inputs to CA3 apparently originate from the amygdaloid complex and endopiriform nucleus (Behan and Haberly 1999; Pikkarainen et al. 1999; Pitkanen et al. 2000) and some of the aminergic nuclei in the brain (Witter and Amaral 2004). Note that CA3, similar to the dentate gyrus, but different to CA1 and the subiculum, does not receive thalamic input (Herkenham 1978; Wouterlood et al. 1990; Shibata 1993; Vertes et al. 2006). No detailed description will be provided here since reviews are available (Pitkanen et al. 2000; Witter and Amaral 2004). Here we will just describe the essentials of the connections with the septal complex (data not shown).

The septal complex, mainly the medial septal nucleus and the vertical limb of the diagonal band of Broca, provides the major subcortical input to CA3 (Amaral and Kurz 1985; Gaykema et al. 1990; Yoshida and Oka 1990). Its origin includes both cholinergic as well as noncholinergic, most likely GABAergic, neurons in the septal complex (Kohler et al. 1984; Amaral and Kurz 1985). The projection terminates bilaterally, most dense in stratum oriens and to a lesser extent in stratum radiatum and lacunosum-moleculare (Nyakas et al. 1987; Gaykema et al. 1990). The noncholinergic projection, which is most likely GABAergic, preferentially terminates onto a variety of interneurons in CA3, including GABAergic interneurons, some of which also express somatostatin (Freund and Antal 1988; Yamano and Luiten 1989; Gulyas et al. 1990). There is a clear topographical organization, such that an overall lateral to medial origin in the septal complex relates to a ventral to dorsal topography in CA3 (note that the 
same holds true for the septal projections to other hippocampal subfields) (Amaral and Kurz 1985). The GABAergic projections to the entire longitudinal extent most likely have a corresponding origin.

It is now quite clear that the only sizable subcortical projection from CA3 is to the septal complex, in particular more to the lateral septal nucleus. This CA3 projection travels via the fimbria and precommissural fornix. The CA3 projection to the septal complex is bilateral; some CA3 fibers cross in the ventral hippocampal commissure to innervate the homologous region of the contralateral lateral septal nucleus. This pathway is topographically organized such that dorsal portions of CA3 project dorsally in the lateral septal nucleus and progressively more ventral portions of CA3 project more ventrally. Moreover, proximal CA3 cells tend to project medially in the lateral septal nucleus, and distally situated CA3 cells terminate more laterally. The organization of the projections from lateral to medial septum, as well as the septal-hypothalamic reciprocal connections, appears in register with the CA3-to-lateral septum projections. This has been taken to indicate the existence of a number of functionally different parallel hippocampal-septal loops (Risold 2004). Although the functional relevance of this organization remains to be established, it likely points toward a functional differentiation in CA3.

A further point of interest relates to the observation that a rather high percentage of CA3 cells (>75\%) gives rise to projections both to CA1 and to the lateral septal nucleus (Swanson et al. 1981). The latter investigators even reported that single CA3 pyramidals most likely collateralize to CA3, CA1, as well as the lateral septum, both on the ipsilateral and contralateral side, implying that a single CA3 pyramidal cell thus influences three different targets bilaterally. Whatever the functional relevance of this observation is, these findings clearly indicate a role for CA3 beyond just an autoassociative network providing input to CA1. A final point with respect to CA3-to-septum projections is that GABAergic neurons in CA3 project to the medial septum (Toth and Freund 1992). These GABAergic neurons most likely belong to the global GABAergic network already mentioned briefly.

\section{Summary and conclusions}

The overall organization of the connectivity of CA3 has been summarized with a focus on anatomical data relevant to the question whether or not CA3 should be considered a homogeneous structure. With this focus in mind, several aspects of CA3 architecture have not been dealt with in great detail, and readers are referred to relevant reviews on this subject (Amaral and Witter 1989; Henze et al. 2000; Pitkanen et al. 2000; Risold 2004; Witter and Amaral 2004; Amaral and Lavenex 2006). The main data summarized concern the intrinsic CA3-to-CA3 connectivity, CA3-to-CA1 projections, connections between CA3 and the dentate gyrus and entorhinal cortex, and, finally, the connections with the septal complex. Taken together, the following conclusions can be formulated. All connections apparently show gradual changes both along the transverse, proximal-to-distal and along the longitudinal, dorsal-to-ventral axes (Figs. 1, 2). The connectional gradients along the transverse axis are paralleled by overall changes in dendritic morphology, suggesting that cells that have a different transverse position are likely to receive different inputs. For example, pyramidal cells located within the two limbs of the dentate gyrus have little or none of their dendrites extending into the stratum lacunosummoleculare, and thus, these cells likely receive little or no direct input from the entorhinal cortex. These cells, however, receive a larger number of mossy fiber terminals on both their apical and basal dendritic trees and are thus under greater influence of the granule cells than are distally located CA3 cells that only receive an apical mossy fiber input. The proximally located cells contribute to the CA3 associational connections only to a limited extent, such that they mainly interact with local CA3 neurons located at closely associated transverse and longitudinal levels. However, they do not differ from all other CA3 neurons regarding their contribution to the projections to CA and the septal complex.

Although it has been suggested that there is an inverse relationship between the transverse position of CA3 neurons and their relative contribution to CA3-to-CA3 at the expense of the CA3-to-CA1 projection, this conclusion does not accurately summarize all available data. It is clear though that proximal CA3 neurons direct more of their overall axonal tree to projections to CA1, and to the dentate for that matter, than they do to CA3. However, more distally located cells contribute as dense to the CA1 projections and contribute more to the associative and commissural CA3 connectivity. Remember that at more ventral levels, the density of the projection from proximal CA3 to the dentate gyrus increases quite substantially at the expense of the projections to CA1. In contrast, it is only in the distal portions of $\mathrm{CA} 3$, and more in particular at dorsal levels, that individual CA3 neurons receive mossy fiber input that originates from widespread parts dorsal to the location of the recipient neuron, thus allowing these distal CA3 neurons to integrate the output of a sizable portion of the dentate gyrus. Taken together, these data do support the proposition that the proximal part of CA3 might be functionally different from the distal part.

In view of the overall connectional architecture, it is tempting to suggest that the intermediate portion is really intermediate in that a gradual shift in overall functional role occurs along the transverse axis from proximal to distal. This suggestion is of interest in the light of the presence of the infrapyramidal mossy fiber pathway in the proximal portion and reports that the transverse distribution of the infrapyramidal mossy fiber input can change depending on behavioral experience. In view of the fact that the infrapyramidal innervation originates primarily from the exposed blade of the dentate gyrus, it would be of interest to establish whether or not an increase in transverse terminal extent relates to a wider distributed origin in the dentate gyrus. This would be of particular interest since in humans this infrapyramidal bundle apparently covers the entire extent of CA3 (Lim et al. 1997).

The associative connections show a longitudinal gradient opposite to that seen in the Schaffer projections. Although this may seem hard to interpret, it does make sense in view of the overall transverse organization of the Schaffer system. As an example, let us consider a cell centered in CA3. This neuron will connect to centrally positioned neurons in CA1 at the corresponding longitudinal level. It will also distribute associative projection to more ventral levels, which will target more proximally positioned CA3 neurons, which in turn will distribute Schaffer collaterals to more distally located cells in CA1. These cells will also be among the targets of the ventrally directed Schaffer projections originating from the parent cell we started with (Fig. 2). A mirrored pattern holds true for the dorsally directed projections. In this way, the overall connectional registry is maintained, and multiple parallel routes may function in these intrahippocampal pathways. These are organized such that the functional contributions derived from portions along the transverse axis will eventually be integrated along the longitudinal axis. One way to understand the full functional integrative power of CA3 would be to study the effects of restricted longitudinal or transverse isolations. Although technically demanding, recently introduced focal gene-transfer protocols (Tonegawa et al. 2003) 
may allow us to achieve such a level of experimental manipulation.

\section{References}

Acsady, L., Kamondi, A., Sik, A., Freund, T., and Buzsaki, G. 1998. GABAergic cells are the major postsynaptic targets of mossy fibers in the rat hippocampus. J. Neurosci. 18: 3386-3403.

Amaral, D.G. 1993. Emerging principles of intrinsic hippocampal organization. Curr. Opin. Neurobiol. 3: 225-229.

Amaral, D.G. and Dent, J.A. 1981. Development of the mossy fibers of the dentate gyrus: I. A light and electron microscopic study of the mossy fibers and their expansions. J. Comp. Neurol. 195: 51-86.

Amaral, D.G. and Kurz, J. 1985. An analysis of the origins of the cholinergic and noncholinergic septal projections to the hippocampal formation of the rat. J. Comp. Neurol. 240: 37-59.

Amaral, D.G. and Lavenex, P. 2006. Hippocampal neuroanatomy. In The hippocampus (eds. P. Andersen et al.), pp. 37-114. Oxford University Press, Oxford, UK.

Amaral, D.G. and Witter, M.P. 1989. The three-dimensional organization of the hippocampal formation: A review of anatomical data. Neuroscience 31: 571-591.

Amaral, D.G., Insausti, R., and Cowan, W.M. 1984. The commissural connections of the monkey hippocampal formation. J. Comp. Neurol. 224: $307-336$

Andersen, P. 1975. Organization of hippocampal neurons and their interconnections. In The hippocampus (eds. R.L. Isaacson and K.H. Pribram), pp. 155-175. Plenum Press, New York.

Andersen, P., Blackstad, T.W., and Lomo, T. 1966. Location and identification of excitatory synapses on hippocampal pyramidal cells. Exp. Brain Res. 1: 236-248.

Andersen, P., Bliss, T.V., Lomo, T., Olsen, L.I., and Skrede, K.K. 1969. Lamellar organization of hippocampal excitatory pathways. Acta Physiol. Scand. 76: 4A-5A.

Behan, M. and Haberly, L.B. 1999. Intrinsic and efferent connections of the endopiriform nucleus in rat. J. Comp. Neurol. 408: 532-548.

Blackstad, T.W. 1956. Commissural connections of the hippocampal region in the rat, with special reference to their mode of termination. J. Comp. Neurol. 105: 417-537.

Blackstad, T.W., Brink, K., Hem, J., and Jeune, B. 1970. Distribution of hippocampal mossy fibers in the rat. An experimental study with silver impregnation methods. J. Comp. Neurol. 138: 433-449.

Buckmaster, P.S., Strowbridge, B.W., and Schwartzkroin, P.A. 1993. A comparison of rat hippocampal mossy cells and CA3c pyramidal cells. J. Neurophysiol. 70: 1281-1299.

Chicurel, M.E. and Harris, K.M. 1992. Three-dimensional analysis of the structure and composition of CA3 branched dendritic spines and their synaptic relationships with mossy fiber boutons in the rat hippocampus. J. Comp. Neurol. 325: 169-182.

Choi, Y.S., Lee, M.Y., Sung, K.W., Jeong, S.W., Choi, J.S., Park, H.J., Kim, O.N., Lee, S.B., and Kim, S.Y. 2003. Regional differences in enhanced neurogenesis in the dentate gyrus of adult rats after transient forebrain ischemia. Mol. Cells 16: 232-238.

Claiborne, B.J., Amaral, D.G., and Cowan, W.M. 1986. A light and electron microscopic analysis of the mossy fibers of the rat dentate gyrus. J. Comp. Neurol. 246: 435-458.

de Almeida, L., Idiart, M., and Lisman, J.E. 2007. Memory retrieval time and memory capacity of the CA3 network: Role of gamma frequency oscillations. Learn. Mem. (this issue). doi: 10.1101/lm.730207.

Demeter, S., Rosene, D.L., and Van Hoesen, G.W. 1985. Interhemispheric pathways of the hippocampal formation, presubiculum, and entorhinal and posterior parahippocampal cortices in the rhesus monkey: The structure and organization of the hippocampal commissures. J. Comp. Neurol. 233: 30-47.

Do, V.H., Martinez, C.O., Martinez Jr., J.L., and Derrick, B.E. 2002. Long-term potentiation in direct perforant path projections to the hippocampal CA3 region in vivo. J. Neurophysiol. 87: 669-678.

Finch, D.M., Nowlin, N.L., and Babb, T.L. 1983. Demonstration of axonal projections of neurons in the rat hippocampus and subiculum by intracellular injection of HRP. Brain Res. 271: 201-216.

Freund, T.F. and Antal, M. 1988. GABA-containing neurons in the septum control inhibitory interneurons in the hippocampus. Nature 336: 170-173.

Freund, T.F. and Buzsaki, G. 1996. Interneurons of the hippocampus. Hippocampus 6: 347-470.

Frotscher, M. and Zimmer, J. 1983. Commissural fibers terminate on non-pyramidal neurons in the guinea pig hippocampus-A combined Golgi/EM degeneration study. Brain Res. 265: 289-293.

Frotscher, M., Leranth, C., Lubbers, K., and Oertel, W.H. 1984. Commissural afferents innervate glutamate decarboxylase immunoreactive non-pyramidal neurons in the guinea pig hippocampus. Neurosci. Lett. 46: 137-143.

Frotscher, M., Seress, L., Schwerdtfeger, W.K., and Buhl, E. 1991. The mossy cells of the fascia dentata: A comparative study of their fine structure and synaptic connections in rodents and primates. J. Comp. Neurol. 312: 145-163.

Frotscher, M., Soriano, E., and Misgeld, U. 1994. Divergence of hippocampal mossy fibers. Synapse 16: 148-160.

Gaarskjaer, F.B. 1986. The organization and development of the hippocampal mossy fiber system. Brain Res. 396: 335-357.

Galimberti, I., Gogolla, N., Alberi, S., Santos, A.F., Muller, D., and Caroni, P. 2006. Long-term rearrangements of hippocampal mossy fiber terminal connectivity in the adult regulated by experience. Neuron 50: 749-763.

Gaykema, R.P., Luiten, P.G., Nyakas, C., and Traber, J. 1990. Cortical projection patterns of the medial septum-diagonal band complex. $J$. Comp. Neurol. 293: 103-124.

Gottlieb, D.I. and Cowan, W.M. 1973. Autoradiographic studies of the commissural and ipsilateral association connection of the hippocampus and detentate gyrus of the rat. I. The commissural connections. J. Comp. Neurol. 149: 393-422.

Gulyas, A.I., Gorcs, T.J., and Freund, T.F. 1990. Innervation of different peptide-containing neurons in the hippocampus by GABAergic septal afferents. Neuroscience 37: 31-44.

Gulyas, A.I., Hajos, N., Katona, I., and Freund, T.F. 2003. Interneurons are the local targets of hippocampal inhibitory cells which project to the medial septum. Eur. J. Neurosci. 17: 1861-1872.

Hara, H., Onodera, H., Kogure, K., and Akaike, N. 1990. The regional difference of neuronal susceptibility in the dentate gyrus to hypoxia. Neurosci. Lett. 115: 189-194.

Hasselmo, M.E., Schnell, E., and Barkai, E. 1995. Dynamics of learning and recall at excitatory recurrent synapses and cholinergic modulation in rat hippocampal region CA3. J. Neurosci. 15: $5249-5262$.

Hausheer-Zarmakupi, Z., Wolfer, D.P., Leisinger-Trigona, M.C., and Lipp, H.P. 1996. Selective breeding for extremes in open-field activity of mice entails a differentiation of hippocampal mossy fibers. Behav. Genet. 26: 167-176.

Henze, D.A., Urban, N.N., and Barrionuevo, G. 2000. The multifarious hippocampal mossy fiber pathway: A review. Neuroscience 98: $407-427$.

Herkenham, M. 1978. The connections of the nucleus reuniens thalami: Evidence for a direct thalamo-hippocampal pathway in the rat. $J$. Comp. Neurol. 177: 589-610.

Ishizuka, N., Weber, J., and Amaral, D.G. 1990. Organization of intrahippocampal projections originating from CA3 pyramidal cells in the rat. J. Comp. Neurol. 295: 580-623.

Ishizuka, N., Cowan, W.M., and Amaral, D.G. 1995. A quantitative analysis of the dendritic organization of pyramidal cells in the rat hippocampus. J. Comp. Neurol. 362: 17-45.

Jaarsma, D., Postema, F., and Korf, J. 1992. Time course and distribution of neuronal degeneration in the dentate gyrus of rat after adrenalectomy: A silver impregnation study. Hippocampus 2: $143-150$.

Kohler, C., Chan-Palay, V., and Wu, J.Y. 1984. Septal neurons containing glutamic acid decarboxylase immunoreactivity project to the hippocampal region in the rat brain. Anat. Embryol. (Berl.) 169: 41-44.

Lauer, M. and Senitz, D. 2006. Dendritic excrescences seem to characterize hippocampal CA3 pyramidal neurons in humans. J. Neural Transm. 113: 1469-1475.

Leranth, C. and Frotscher, M. 1983. Commissural afferents to the rat hippocampus terminate on vasoactive intestinal polypeptide-like immunoreactive non-pyramidal neurons. An EM immunocytochemical degeneration study. Brain Res. 276: 357-361.

Li, X.G., Somogyi, P., Ylinen, A., and Buzsaki, G. 1994. The hippocampal CA3 network: An in vivo intracellular labeling study. $J$. Comp. Neurol. 339: 181-208.

Lim, C., Blume, H.W., Madsen, J.R., and Saper, C.B. 1997. Connections of the hippocampal formation in humans: I. The mossy fiber pathway. J. Comp. Neurol. 385: 325-351.

Lipp, H.P., Schwegler, H., Heimrich, B., Cerbone, A., and Sadile, A.G. 1987. Strain-specific correlations between hippocampal structural traits and habituation in a spatial novelty situation. Behav. Brain Res. 24: 111-123.

Lipp, H.P., Schwegler, H., Heimrich, B., and Driscoll, P. 1988. Infrapyramidal mossy fibers and two-way avoidance learning: Developmental modification of hippocampal circuitry and adult behavior of rats and mice. J. Neurosci. 8: 1905-1921.

Lorente de Nó, R. 1934. Studies on the structure of the cerebral cortex. II. Continuation of the study of the ammonic system. J. Psychol. Neurol. 46: 113-177.

MacVicar, B.A. and Dudek, F.E. 1980. Local synaptic circuits in rat 
hippocampus: interactions between pyramidal cells. Brain Res. 184: $220-223$

Marr, D. 1971. Simple memory: A theory for archicortex. Philos. Trans. R. Soc. Lond. B Biol. Sci. 262: 23-81.

McLardy, T. and Kilmer, W.L. 1970. Hippocampal circuitry. Am. Psychol. 25: $563-566$.

McNaughton, B.L. and Morris, R.G.M. 1987. Hippocampal synaptic enhancement and information storage within a distributed memory system. Trends Neurosci. 10: 408-415.

Miles, R. and Wong, R.K. 1983. Single neurones can initiate synchronized population discharge in the hippocampus. Nature 306: $371-373$.

Miles, R. and Wong, R.K. 1986. Excitatory synaptic interactions between CA3 neurones in the guinea-pig hippocampus. J. Physiol. 373: $397-418$

Nafstad, P.H. 1967. An electron microscope study on the termination of the perforant path fibres in the hippocampus and the fascia dentata. Z. Zellforsch. Mikrosk. Anat. 76: 532-542.

Nyakas, C., Luiten, P.G., Spencer, D.G., and Traber, J. 1987. Detailed projection patterns of septal and diagonal band efferents to the hippocampus in the rat with emphasis on innervation of CA1 and dentate gyrus. Brain Res. Bull. 18: 533-545.

Pikkarainen, M., Ronkko, S., Savander, V., Insausti, R., and Pitkanen, A 1999. Projections from the lateral, basal, and accessory basal nuclei of the amygdala to the hippocampal formation in rat. J. Comp. Neurol. 403: 229-260.

Pitkanen, A., Pikkarainen, M., Nurminen, N., and Ylinen, A. 2000. Reciprocal connections between the amygdala and the hippocampal formation, perirhinal cortex, and postrhinal cortex in rat. A review. Ann. N. Y. Acad. Sci. 911: 369-391.

Raisman, G., Cowan, W.M., and Powell, T.P. 1966. An experimental analysis of the efferent projection of the hippocampus. Brain 89: 83-108.

Ramón, Y. and Cajal, S. 1911. Histologie du Systeme Nerveux de l'Homme et des Vertebres. Maloine, Paris.

Risold, P.Y. 2004. The septal region. In The rat brain (ed. G. Paxinos), pp. 605-632. Elsevier Academic Press, San Diego.

Schaffer, K. 1892. Beitrag zur Histologie der Ammonshornformation. Arch. Mikr. Anat. 39: 611-632.

Scharfman, H.E. 1994. Evidence from simultaneous intracellular recordings in rat hippocampal slices that area CA3 pyramidal cells innervate dentate hilar mossy cells. J. Neurophysiol. 72: 2167-2180.

Scharfman, H.E., Sollas, A.L., Smith, K.L., Jackson, M.B., and Goodman, J.H. 2002. Structural and functional asymmetry in the normal and epileptic rat dentate gyrus. J. Comp. Neurol. 454: 424-439.

Schopke, R., Wolfer, D.P., Lipp, H.P., and Leisinger-Trigona, M.C. 1991. Swimming navigation and structural variations of the infrapyramidal mossy fibers in the hippocampus of the mouse. Hippocampus 1: $315-328$.

Seress, L., Gulyas, A.I., and Freund, T.F. 1992. Pyramidal neurons are immunoreactive for calbindin D28k in the CA1 subfield of the human hippocampus. Neurosci. Lett. 138: 257-260.

Shepherd, G.M. and Harris, K.M. 1998. Three-dimensional structure and composition of CA3 $\rightarrow$ CA1 axons in rat hippocampal slices: Implications for presynaptic connectivity and compartmentalization. J. Neurosci. 18: 8300-8310.

Shibata, H. 1993. Direct projections from the anterior thalamic nuclei to the retrohippocampal region in the rat. J. Comp. Neurol. 337: 431-445

Sik, A., Tamamaki, N., and Freund, T.F. 1993. Complete axon arborization of a single CA3 pyramidal cell in the rat hippocampus, and its relationship with postsynaptic parvalbumin-containing interneurons. Eur. J. Neurosci. 5: 1719-1728.

Sik, A., Ylinen, A., Penttonen, M., and Buzsaki, G. 1994. Inhibitory CA1-CA3-hilar region feedback in the hippocampus. Science 265: $1722-1724$

Sik, A., Penttonen, M., Ylinen, A., and Buzsaki, G. 1995. Hippocampal CA1 interneurons: An in vivo intracellular labeling study. J. Neurosci. 15: $6651-6665$.

Somogyi, P. and Klausberger, T. 2005. Defined types of cortical interneurone structure space and spike timing in the hippocampus. J. Physiol. 562: 9-26.

Soriano, E. and Frotscher, M. 1993. Spiny nonpyramidal neurons in the CA3 region of the rat hippocampus are glutamate-like immunoreactive and receive convergent mossy fiber input. J. Comp. Neurol. 333: 435-448.

Sorra, K.E. and Harris, K.M. 1993. Occurrence and three-dimensional structure of multiple synapses between individual radiatum axons and their target pyramidal cells in hippocampal area CA1. $J$ Neurosci. 13: 3736-3748.

Steward, O. 1976. Topographic organization of the projections from the entorhinal area to the hippocampal formation of the rat. J. Comp.
Neurol. 167: 285-314.

Steward, O. and Scoville, S.A. 1976. Cells of origin of entorhinal cortical afferents to the hippocampus and fascia dentata of the rat. J. Comp. Neurol. 169: 347-370.

Swanson, L.W., Wyss, J.M., and Cowan, W.M. 1978. An autoradiographic study of the organization of intrahippocampal association pathways in the rat. I. Comp. Neurol. 181: 681-715.

Swanson, L.W., Sawchenko, P.E., and Cowan, W.M. 1980. Evidence that the commissural, associational and septal projections of the region inferior of the hippocampus arise from the same neurons. Brain Res. 197: 207-212.

Swanson, L.W., Sawchenko, P.E., and Cowan, W.M. 1981. Evidence for collateral projections by neurons in Ammon's horn, the dentate gyrus, and the subiculum: A multiple retrograde labeling study in the rat. J. Neurosci. 1: 548-559.

Tamamaki, N. and Nojyo, Y. 1993. Projection of the entorhinal layer II neurons in the rat as revealed by intracellular pressure-injection of neurobiotin. Hippocampus 3: 471-480.

Tonegawa, S., Nakazawa, K., and Wilson, M.A. 2003. Genetic neuroscience of mammalian learning and memory. Philos. Trans. $R$. Soc. Lond. B Biol. Sci. 358: 787-795.

Toth, K. and Freund, T.F. 1992. Calbindin D28k-containing nonpyramidal cells in the rat hippocampus: Their immunoreactivity for GABA and projection to the medial septum. Neuroscience 49: 793-805.

Treves, A. and Rolls, E.T. 1994. Computational analysis of the role of the hippocampus in memory. Hippocampus 4: 374-391.

Turner, D.A., Li, X.G., Pyapali, G.K., Ylinen, A., and Buzsaki, G. 1995. Morphometric and electrical properties of reconstructed hippocampal CA3 neurons recorded in vivo. J. Comp. Neurol. 356: $580-594$

van Groen, T. and Wyss, J.M. 1988. Species differences in hippocampal commissural connections: Studies in rat, guinea pig, rabbit, and cat. J. Comp. Neurol. 267: 322-334.

van Groen, T., Miettinen, P., and Kadish, I. 2003. The entorhinal cortex of the mouse: organization of the projection to the hippocampal formation. Hippocampus 13: 133-149.

Vertes, R.P., Hoover, W.B., Do Valle, A.C., Sherman, A., and Rodriguez, J.J. 2006. Efferent projections of reuniens and rhomboid nuclei of the thalamus in the rat. J. Comp. Neurol. 499: 768-796.

Voneida, T.J., Vardaris, R.M., Fish, S.E., and Reiheld, C.T. 1981. The origin of the hippocampal commissure in the rat. Anat. Rec. 201: 91-103.

Westrum, L.E. and Blackstad, T.W. 1962. An electron microscopic study of the stratum radiatum of the rat hippocampus (regio superior, CA 1) with particular emphasis on synaptology. J. Comp. Neurol. 119: 281-309.

Witter, M.P. 1989. Connectivity of the rat hippocampus. In The hippocampus - New vistas (eds. V. Chan-Palay and C. Köhler), pp. 53-69. Allen R. Liss, New York.

Witter, M.P. 1993. Organization of the entorhinal-hippocampal system: A review of current anatomical data. Hippocampus 3: 33-44.

Witter, M.P. 2006. Connections of the subiculum of the rat: Topography in relation to columnar and laminar organization. Behav. Brain Res. 174: $251-264$

Witter, M.P. 2007. The perforant path: Projections from the entorhinal cortex to the dentate gyrus. Prog. Brain Res. 163: 43-61.

Witter, M.P. and Amaral, D.G. 1991. Entorhinal cortex of the monkey: V. Projections to the dentate gyrus, hippocampus, and subicular complex. J. Comp. Neurol. 307: 437-459.

Witter, M.P. and Amaral, D.G. 2004. Hippocampal formation. In The rat nervous system (ed. G. Paxinos), pp. 635-704. Elsevier Academic Press, San Diego.

Witter, M.P., Groenewegen, H.J., Lopes da Silva, F.H., and Lohman, A.H. 1989a. Functional organization of the extrinsic and intrinsic circuitry of the parahippocampal region. Prog. Neurobiol. 33: $161-253$.

Witter, M.P., Van Hoesen, G.W., and Amaral, D.G. 1989b. Topographical organization of the entorhinal projection to the dentate gyrus of the monkey. J. Neurosci. 9: 216-228.

Witter, M.P., Jorritsma-Byham, B., and Wouterlood, F.G. 1992. Perforant pathway projections to the ammons horn and the subiculum in the rat; an electron microscopical PHA-L study. Soc. Neurosci. Abstr. 1: 323 .

Wittner, L., Henze, D.A., Zaborszky, L., and Buzsaki, G. 2006. Hippocampal CA3 pyramidal cells selectively innervate aspiny interneurons. Eur. J. Neurosci. 24: 1286-1298.

Wittner, L., Henze, D.A., Zaborsky, L., and Buzsaki, G. 2007. Three-dimensional reconstruction of the axon arbor of a CA3 pyramidal cell recorded and filled in vivo. Brain Struct. Funct. 212: $75-83$.

Wouterlood, F.G., Saldana, E., and Witter, M.P. 1990. Projection from 
the nucleus reuniens thalami to the hippocampal region: Light and electron microscopic tracing study in the rat with the anterograde tracer Phaseolus vulgaris-leucoagglutinin. J. Comp. Neurol.

296: $179-203$.

Yamano, M. and Luiten, P.G. 1989. Direct synaptic contacts of medial septal efferents with somatostatin immunoreactive neurons in the rat hippocampus. Brain Res. Bull. 22: 993-1001.

Yeckel, M.F. and Berger, T.W. 1990. Feedforward excitation of the hippocampus by afferents from the entorhinal cortex: Redefinition of the role of the trisynaptic pathway. Proc. Natl. Acad. Sci. 87: 5832-5836.

Yoshida, K. and Oka, H. 1990. Topographical distribution of septohippocampal projections demonstrated by the PHA-L immunohistochemical method in rats. Neurosci. Lett. 113: 247-252.

Received August 2, 2007; accepted in revised form September 12, 2007. 


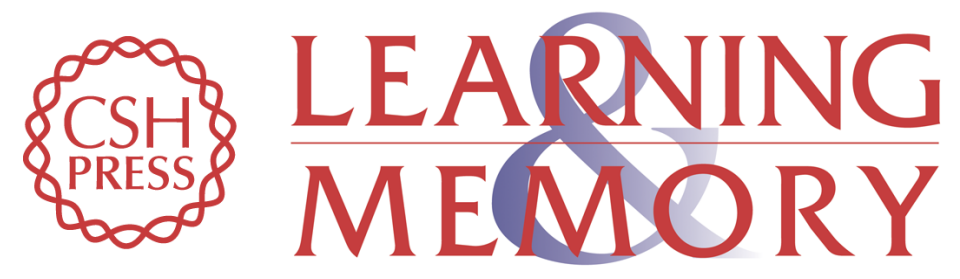

\section{Intrinsic and extrinsic wiring of CA3: Indications for connectional heterogeneity}

Menno P. Witter

Learn. Mem. 2007, 14:

Access the most recent version at doi:10.1101//m.725207

References This article cites 99 articles, 11 of which can be accessed free at:

http://learnmem.cshlp.org/content/14/11/705.full.html\#ref-list-1

License

Email Alerting Receive free email alerts when new articles cite this article - sign up in the box at the Service top right corner of the article or click here. 